\title{
Erratum to: Corynebacterium glutamicum as a potent biocatalyst for the bioconversion of pentose sugars to value-added products
}

Vipin Gopinath • Anusree Murali • Kiran S. Dhar • K. Madhavan Nampoothiri

Published online: 13 December 2011

(C) Springer-Verlag 2011

Erratum to: Appl Microbiol Biotechnol

DOI 10.1007/s00253-011-3686-4

In the original publication, Figures $1-3$ and it's corresponding legends contains error. The correct version is given below:

Figures 1, 2 and 3.

The online version of the original article can be found at http://dx.doi. org/10.1007/s00253-011-3686-4.

V. Gopinath · A. Murali · K. S. Dhar · K. M. Nampoothiri $(\square)$ Biotechnology Division, National Institute for Interdisciplinary

Science and Technology (NIIST), CSIR,

Trivandrum 695 019, Kerala, India

e-mail: madhavan85@hotmail.com 
Fig. 1 The Caulobacterial pathway for xylose utilization

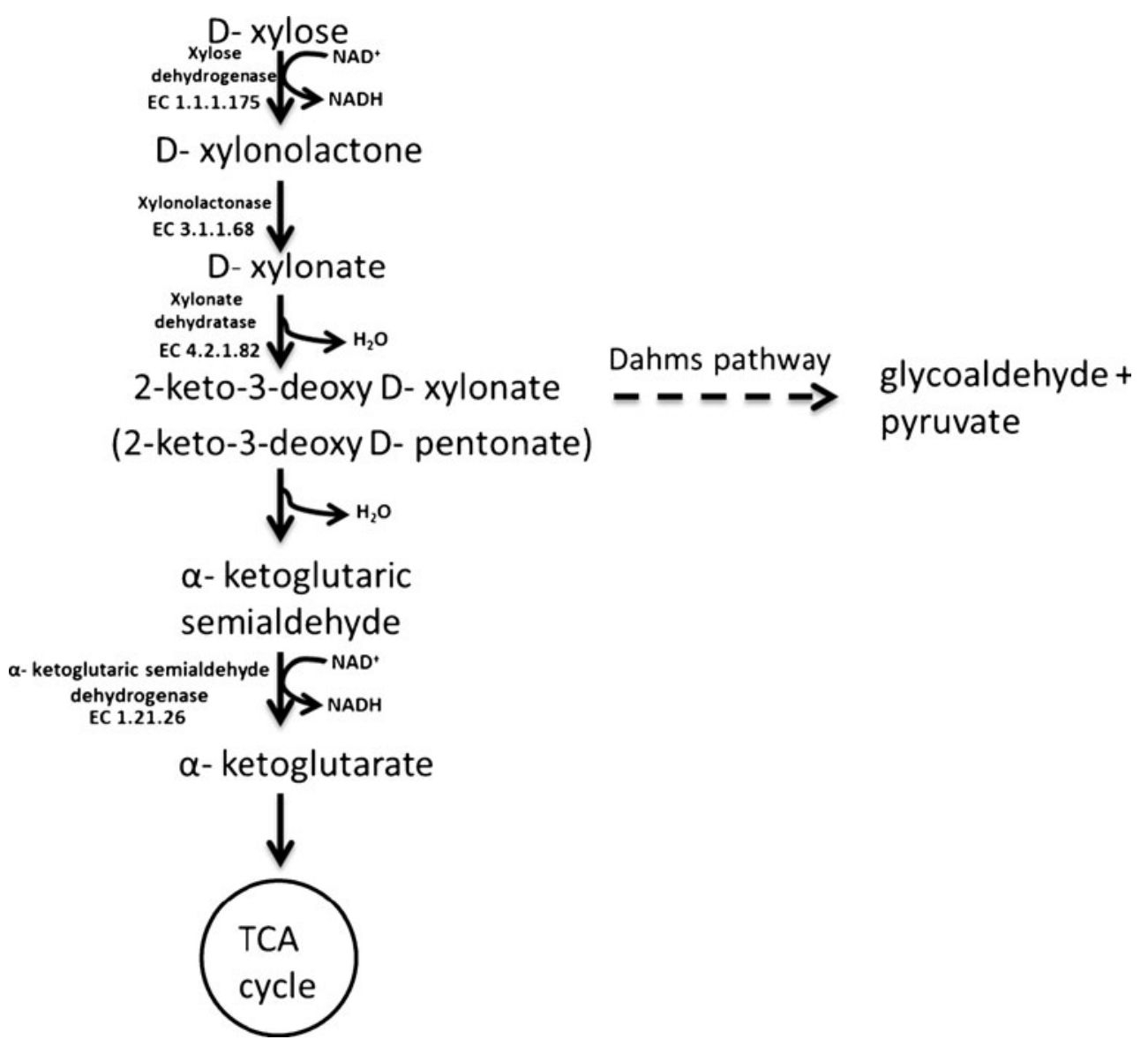

Fig. 2 Bacterial isomerase pathways for xylose and arabinose
Pentose phosphate

pathway

Arabinose EC 5.3.1.4 $\downarrow \begin{aligned} & \text { Arabinose } \\ & \text { isomerase }\end{aligned}$

Ribulose

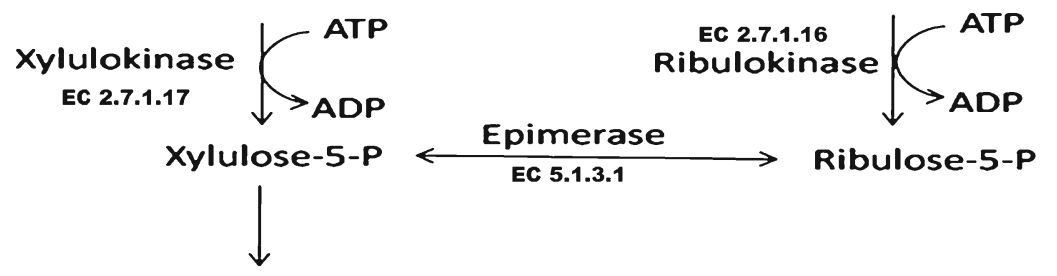




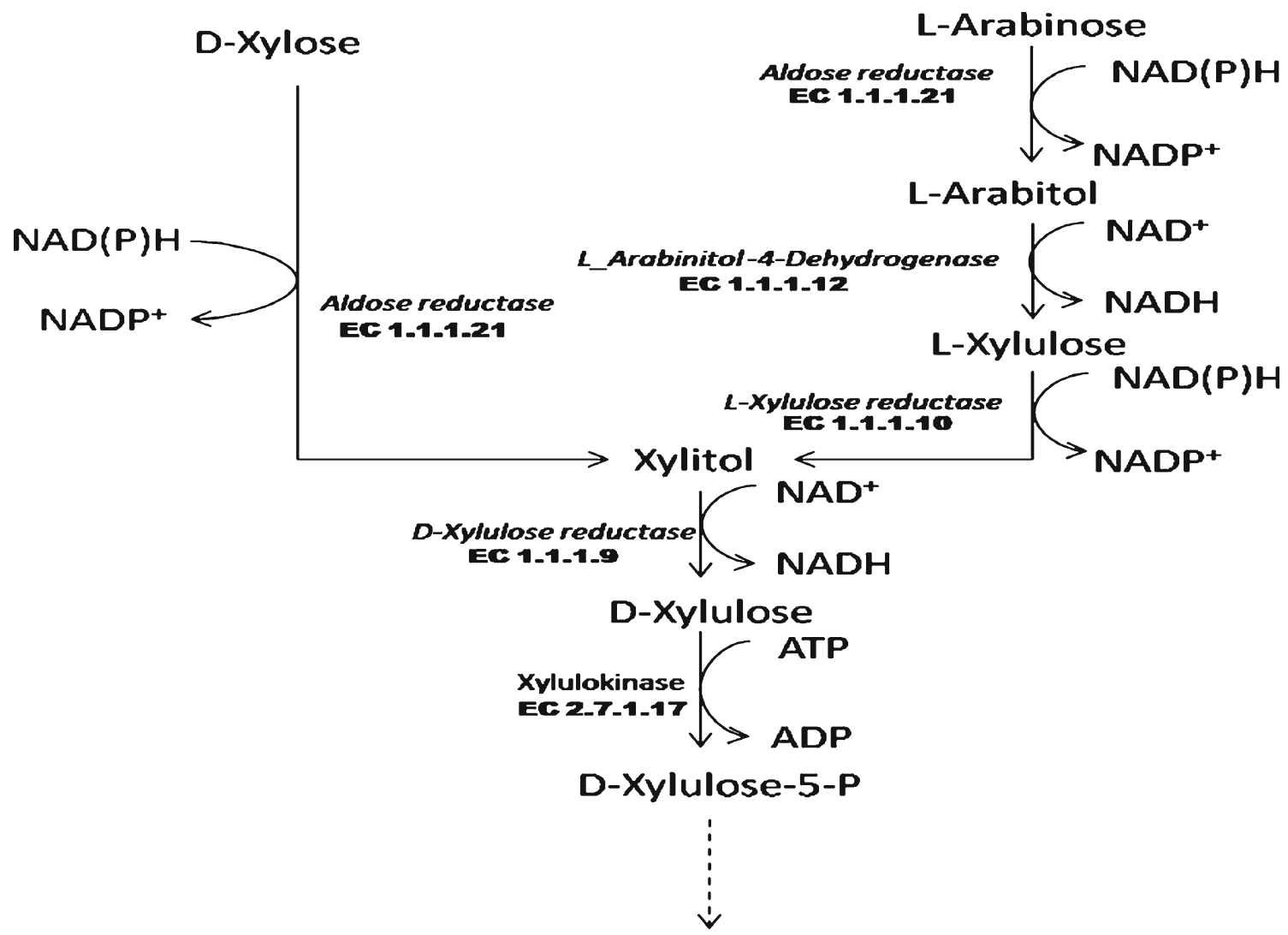

Fig. 3 The fungal reductive pathway for xylose and arabinose utilization 